\title{
Organizational diversity and innovation potential of EU-funded research projects
}

\author{
Daniel Nepelski ${ }^{1}$ Giuseppe Piroli $^{2}$
}

Published online: 15 September 2017

(C) The Author(s) 2017. This article is an open access publication

\begin{abstract}
Impact evaluations of collaborative research projects usually focus on private benefits of participants, e.g. their turnover or employment growth. We study the innovative performance of collaborative research projects and how it depends on the organizational diversity of participating organizations. Our population includes participants to EC-funded collaborative research projects that are considered as key organisations behind delivering innovations. The focus on innovative rather than, for example, financial outcomes allows us to assess the transformative effect of publically-funded collaborative research. We show that the innovative potential of research output of homogenous partnerships, e.g. between two SMEs or two large companies, is likely to be higher, as compared to heterogeneous partnerships, e.g. an SME and a large company. The impact of universities on the potential of innovations is unclear. The total number of key organizations in delivering an innovation has negative impact on its potential. Neither project funding nor duration affects the potential of innovation. Our results implicitly show that, depending on the type of organization and consortium design, there are different incentives to contribute to innovative efforts and opportunities to appropriate their benefits.
\end{abstract}

Keywords Collaborative R\&D projects · Innovation policy · Framework programme $\cdot$ Small and medium-sized enterprises $\cdot$ Universities $\cdot$ European Commission

JEL Classification L52 $\cdot \mathrm{L} 53 \cdot \mathrm{O} 31 \cdot \mathrm{O} 32 \cdot \mathrm{O} 25$

The views expressed are those of the authors and may not in any circumstances be regarded as stating an official position of the European Commission.

Daniel Nepelski

Daniel.Nepelski@ec.europa.eu

1 Joint Research Centre, European Commission, Calle del Inca Garcilaso 3, 41092 Seville, Spain

2 DG Employment, Social Affairs and Inclusion, European Commission, Brussels, Belgium 


\section{Introduction}

The European Union's (EU) Framework Programme (FP) constitutes an important share in R\&D expenditures in Europe (EC 2007). ${ }^{1}$ In addition to finance science and technology development, one of their main objectives of the FP is to foster international collaboration among research organizations and private firms, both large and SMEs. For example, the Cooperation program was the core of the 7th FP and represented two-thirds of its overall budget. It aimed at fostering collaborative research across Europe and other partner countries through projects by transnational consortia of industry and academia. The objective of the FP is increasingly shifting from sponsoring basic research to becoming a main factor behind economic and social transformation (EC 2015). This transformation takes place through enhancing the application of scientific results to solve known problems and to increase the commercialization of technology (Leyden and Link 2015; Mazzucato 2013). Public sector entrepreneurship triggers the transformation primarily by increasing the effectiveness of knowledge networks; that is, by increasing the heterogeneity of experiential ties among economic units and the ability of those same economic units to exploit such diversity (Audretsch and Link 2016).

This paper tackles the issue of innovation potential of FP7 research projects and how it is related to the organization diversity of organizations involved in the development of innovations. So far most of impact assessments of FP programs are limited to the accounting for scientific output and filled patent applications (EC-CONNECT 2014) and to analyze benefits to participating organizations. Assessment studies focus mainly on profitability or employment change of participating firms (Aguiar and Gagnepain 2013; Barajas et al. 2012; Bayona-Sáez and García-Marco 2010; Belderbos et al. 2004). There are few attempts that go beyond this by analyzing, for example, social benefits (Georghiou 1999; Link and Scott 2004). Hence, by focusing on the innovative output, we introduce a new way of analysing the impact of EC-funded research projects.

Regarding the issue of organizational diversity, by distinguishing between different organizational forms, we introduce the notion of inequality in terms of input and effort performed by various organizations with respect to innovating in publically-funded research projects. This can be related to unequal incentives or appropriation opportunities related to the organizational form of participants (Röller et al. 2007).

We proceed in two steps. First, we use the output of the assessment of innovation potential of over 500 innovations identified in FP7 research projects in the domain of information and communication technologies (ICT). This is done using a formal innovation potential assessment framework and aggregating answers to a novel innovation survey questionnaire used in the assessment of FP7 projects. The aggregated indicators capture the level of innovation readiness, management and market potential and through a composite indicator the overall potential of an innovation. Second, we examine the relationship between the potential of innovations and the diversity of partnerships involved in the development of these innovations. By partnership we mean the type of organizations that were identified by reviewers of the FP7 projects as "key organisation(s) in the project delivering an innovation". We distinguish between homogenous, e.g. two universities, or two SMEs, and heterogeneous partnerships, e.g. at least one university and one SME, or at least one SME and one large company.

\footnotetext{
1 The FP7 has a budget of over $€ 50$ billion with $€ 9$ billion allocated to ICT for the period from 2007 to 2013 (EC 2007). In comparison, the ICT sector R\&D annual expenditures in the EU reached almost $€ 30$ billion in 2011 (JRC 2014).
} 
In this paper, we use data provided by the Innovation Radar (IR) project, an EC support initiative launched in August 2013 (De Prato et al. 2015). In its first release, the IR project collected data between May 2014 and January 2015 on 279 ICT FP7 and Competitiveness and Innovation Framework Programme (CIP) projects or $10.6 \%$ of all ICT FP7/CIP projects. According to the first findings, an average ICT FP7 project produces 2 innovations. However, their commercialisation potential varies and further nurturing is needed to exploit their potential (De Prato et al. 2015). Access to financing, IPR and regulation are among the factors that are considered as major bottlenecks to commercial exploitation of those innovations. At the same time, partnership with other company, expanding to more markets and business plan development are among the most frequent needs of organizations identified as key innovators.

The results show that the design of project consortia is more important than project funding or duration. On the one hand, this has some implications for organizations participating to collaborative research projects. On the other hand, it provides some insights on how to help consortia to commercialise their innovations by providing support that takes into account the characteristics of the participating organizations.

The current paper is structured as follows: Sect. 2 reviews some key findings of the existing evidence on the performance of $R \& D$ partnerships and formulates the research questions that we tackle. Section 4 explains the topic of assessment of innovation and technology-based ventures and the methodology of constructing innovation potential assessment indicators and presents data used in the current study. Section 5 show a descriptive analysis of innovations and Sect. 6 present the results of the innovation potential assessment. Section 7 concludes.

\section{Literature review}

\subsection{The rationale for public support to $R \& D$ collaboration}

R\&D collaboration increases a firm's incentives to perform some types of R\&D activity, mainly with results difficult to be appropriated (Katz 1986). Joint R\&D efforts minimise issue of appropriation of $\mathrm{R} \& \mathrm{D}$ outcomes and increase private benefits of a firm. Companies are willing to join forces provided that they can access to complementary resources (Caloghirou et al. 2001; Kogut 1988; Sakakibara 1997), overcome transaction costs, or reduce risk associated with uncertain $R \& D$ outcomes (Hagedoorn et al. 2000). R\&D collaborations do not only benefit firms involved in such activities. The existence of larger collaboration networks increases also the innovation performance of individual locations and regions (Asheim et al. 2011; Tödtling and Trippl 2005). Thus, considering the positive private and social benefits of $R \& D$ collaboration, the general conclusion is that there is room for public intervention in overcoming the problems of coordination and risk sharing in knowledge production (Davenport et al. 1998). Therefore, one of the main features of the Framework Programmes of the EC is an increasing emphasis on collaborative research, both within the EU and with external research partners.

Besides the additionally effect of publically-sponsored research joint-ventures (RJVs), there is also the issue of their directionality (Mazzucato 2016). In the perspective of the public sector entrepreneurship, the European collaborative R\&D projects initiatives are expected to trigger technological and economic transformation by creating and exploiting networks that generate socially desired innovations (Leyden 2016; Link 2016). The public 
sector seeks to increase the effectiveness of knowledge networks and gives rise to a discovery process by which organizations attempt to bring the desired innovation to the market and or society (Audretsch and Link 2016).

\subsection{The role of diversity in collaborative research projects}

Diversity is expected to play a positive role in collaborative research projects by increasing the level of novelty and facilitating discovery of cross-border applications and solutions. At organization level, rooted in different experiences, culture, organizational form, technological endowments, diversity promotes constructive exchange of capabilities, technological and administrative innovation and entry into new product markets (Boeker 1997; Cox 1993; Knight et al. 1999; Perkins and Fields 2010). It leads to greater variance in ideas, creativity, and innovation. Diversity opens up new perspectives and opportunities to expand into new geographic locations (Barkema and Shvyrkov 2007). According to Diánez-González and Camelo-Ordaz (2016), diversity influences the level of entrepreneurial orientation. The presence of non-academic managers is a key factor in the academic spinoffs' higher levels of entrepreneurial orientation. Demographic and cultural diversity is also related to the level of novelty of new ventures. A high level of innovativeness requires frequent and rich interactions among members of an organization. Similarity facilitates exchange of subjective and ambiguous information while maintaining unity and continuity of purpose. At the same time, to learn, recognize and accommodate new opportunities, a team must be able to span the boundaries between itself and its environment. Its members must represent an array of diverse talents and capabilities. Such breadth facilitates learning and adaptation and is driven by dissimilarity (Amason et al. 2006). The benefits of diversity come at a cost. Under some circumstances, the coordination costs may outweigh the positive ones (Ancona and Caldwell 1992).

\subsection{Diversity and performance of publically funded research projects}

Against this background, one of the key questions in facilitating European knowledge networks is the issue of their composition and structure. FP encourages collaboration between public and private organization and increasing emphasises the involvement small and medium size enterprises (SEMs) (Caloghirou et al. 2001; Santoro and Chakrabarti 2002). It is argued that small firms participate in larger R\&D project that involve, among others, universities in order to get access to novel knowledge and technology and to benefit from spillovers (Chun and Mun 2012). Additional benefits of R\&D collaboration between firms and universities include increased productivity (Cunningham and Link 2015; Link and Rees 1990); higher probability of commercialisation R\&D results (Hewitt-Dundas et al. 2017; Link and Ruhm 2009), and a business's economies of technological scope increase with university involvement (Leyden and Link 2013, 2015).

However, collaboration between partners of various sizes and backgrounds does not happen smoothly. One of the reasons is diverging interests, motivations to join a consortium and incentives to provide input to common project. SMEs report a strong strategic alignment with FP projects and explicit goals related to innovation outputs such as developing a prototype, a patentable technology, or a complementary technology that will directly enhance their competitiveness (Polt et al. 2008). They focus on projects with an applied orientation and engage only in cooperative agreements that are likely to yield tangible benefits guaranteeing them immediate survival and growth. In contrast, large firms appeared much less inclined to commercialise right out of the project, compared to highly 
committed-to-commercialisation SMEs. Because of the more marginal role of FP projects, larger companies reported weaker strategic alignment and less explicit goals. Participation in collaborative R\&D projects is meant as technology watch, acquisition of new knowledge and building partnerships (Hernan et al. 2003). Universities, on the other hand, seek in RJVs complementary resources that allow them to advance research (Caloghirou et al. 2001; Polt et al. 2008). Based on their scientific capabilities, universities engage in research collaborations on the basis of research contents (Carayol 2003). The main criterion for collaboration is that it feeds of a university's own research agenda (Link and Scott 2005). Commercialisation is not the main objective but rather the building up of new knowledge and technology and the investigation of new research areas.

Considering that different types of organizations have different objectives and incentives to be involved into RJV, we can assume that these differences are likely to affect the inputs from various partners, the outcomes of collaboration and how their results are appropriated by among them (Link 2015; Link and Siegel 2005). For example, large firms are less willing to share their economic knowledge with smaller rivals and have a preference to collaborate with other large firms in order to maximize the internalization of spillovers (Röller et al. 2007). Diversity in firm size and efficiency level, can also impede effective R\&D collaboration (Siebert 1996). Similar considerations apply to collaborations between companies and universities (Bronwyn et al. 2003). Participation of universities in RJV does not seem to increase technological performance of the project and the outcomes depend on the company size (Okamuro 2007). In general, SMEs can benefit more from R\&D collaboration with universities rather than larger firms. Hence, although European research networks are characterised with institutional diversity, large industrial partners represent only a small share of the all participants (Pandza et al. 2011).

Although the FP seeks variety in size, organizational type and geographical location of participants to grow the diversity of research networks, this increases coordination cost and creates managerial challenges in communicating and sharing knowledge across national and institutional borders. Overall, this may not be desired by all partners and does not guarantee a successful collaboration. Therefore, the design of a consortium is more important than the level of $R \& D$ input in explaining the technological performance (Branstetter and Sakakibara 2002; Kastrinos 1994). In particular, such organizational characteristics of consortia as technological and product market proximity of members, level of centralization, diversity of members etc., are particularly important for the positive outcomes of such collaborations.

\section{Research questions}

Taking into account the above discussion, the question we address in this paper concerns the relationship between innovative performance of research projects and organizational diversity of RJVs. Existing research efforts analysing the impact of RJVs, including publically-funded, focus on, for example, organization-level outcomes, e.g. productivity and employment increases (Barajas et al. 2012; Bayona-Sáez and García-Marco 2010). Instead, we look at the innovation output of publically-funded RJVs. The focus on innovative output links the analysis to the strand of literature on public sector entrepreneurship (Leyden and Link 2015; Mazzucato 2013). This perspective views the role of public sector and technology and innovation policy not only as a sponsor of basic research, but as a main factor behind economic and social transformation. This transformation is expected through 
directed innovation relying on the application of scientific results to solve known problems and to increase the commercialization of technology. Our study differs also from existing ones by observing project-level rather than individual performance.

Recognizing that there is a link between design of RJVs and their performance, we specifically look at the relationship between the diversity of organizations involved in developing an innovative product or service within publically-funded research project and its innovation potential. Regarding organizational diversity, we distinguish between homogenous, e.g. university and university or SME and SME, and heterogeneous, e.g. university and large company or large company and SME, partnerships. We are interested in the question of which type of partnerships are associated with higher innovation potential of $\mathrm{R} \& \mathrm{D}$ outcomes. Innovation potential is related to innovation readiness, management and market potential. By looking at both the aggregate score of the innovation potential composite indicator and the sub-composite indicators, we are additionally interested in the question of how the composition of innovation partnership perform with respect to such elements of the process of technology commercialisation as innovation readiness, management and market potential.

\section{Methodology and data}

This section describes the methodology applied in this paper. It uses the output of the Innovation Radar (IR) project, an EC support initiative to assess the innovation potential of innovations developed within the FP research projects and identify the bottlenecks to their commercialisation (De Prato et al. 2015). Below we explain the innovation potential assessment criteria used in the current study (Sect. 4.1) and the measures of diversity of innovation partnerships (Sect. 4.2).

\subsection{Innovation potential assessment framework}

The principles of the IR rest on the concept of innovation and new technology venture assessment. This type of activity is commonly performed by large research organizations, technology-based companies, universities or venture capitalists screening companies or projects with respect to their new product development, technological readiness and market potential of new products (De Coster and Butler 2005; Liao and Witsil 2008). In general terms, one can differentiate between two types of assessment of new innovations and technology projects. One is a process-based and the other culturally-based (Cooper and Kleinschmidt 1997; Khurana and Rosenthal 1998). Table 1 provides a synthesis of the main characteristics of the two approaches.

The process-based assessment uses established procedures for assessing proposals for funding. It is mainly used by, for example, banks granting loans to small, technology-based enterprises, or large research organizations, e.g. the National Aeronautics and Space Administration (NASA), when choosing new products to develop from various technological projects. The process-based assessment tends to be regular, with proposals arriving and being reviewed on a methodological basis. A regular process warrants an investment in methods and tools that lend themselves to comparing several options simultaneously and that keep records so that future opportunities can be compared with past opportunities. In contrast, the culturally-based approach does not assess all projects against a formal methodology. Instead, assessment is based on the assessor's experiences both individually 
Table 1 Approaches to innovation and technology-based ventures assessment. Source: De Prato et al. (2015) based on De Coster and Butler (2005)

\begin{tabular}{|c|c|c|}
\hline & \multicolumn{2}{|l|}{ Approach type } \\
\hline & Process-based & Culturally-based \\
\hline Methodology & $\begin{array}{l}\text { Automatic or semi-automatic, deploying pre- } \\
\text { defined questionnaires and assessment } \\
\text { templates }\end{array}$ & $\begin{array}{l}\text { Individual evaluation based on a set of } \\
\text { pre-defined criteria } \\
\text { Intensive due-diligence of company, its } \\
\text { staff and market }\end{array}$ \\
\hline $\begin{array}{l}\text { Scope and } \\
\text { intensity }\end{array}$ & $\begin{array}{l}\text { A set of pre-defined dimensions with a list of } \\
\text { questions }\end{array}$ & In-depth evaluation of individual cases \\
\hline Outcome & Selection based on a relative or absolute score & $\begin{array}{l}\text { Selection based on the in-depth analysis } \\
\text { and consensus of an evaluating team }\end{array}$ \\
\hline $\begin{array}{l}\text { Number of } \\
\text { assessments }\end{array}$ & Many & Few \\
\hline Examples & $\begin{array}{l}\text { Banks granting loans } \\
\text { Evaluations performed by research funding- } \\
\text { agencies } \\
\text { Large corporations evaluating internal research } \\
\text { projects }\end{array}$ & $\begin{array}{l}\text { Venture capitalist } \\
\text { Business angels }\end{array}$ \\
\hline
\end{tabular}

and collectively. Business angels and venture capitalists are the most common users of the culturally-based approach to assessing new technology ventures. The assessment is usually done on a case-by-case basis by a team consisting of experts with different backgrounds.

Within this framework, the IR methodology can be seen as a process-based approach to innovation and new technology assessment. It applies a structured framework to assessing the potential of innovations and innovative capacity of organisations that play a key role in delivering these innovations.

In order to provide synthetic comparable results for further analysis and interpretation, the IR innovation potential assessment framework uses three assessment criteria that are commonly referred to in the context of innovation potential assessment exercises: Market Potential, Innovation Readiness and Innovation Management (De Coster and Butler 2005; Liao and Witsil 2008). These three assessment criteria are expected to capture the potential value an innovation can generate, its market readiness and, finally, the quality of the commercialisation process. The choice of these three elements as the determinants of innovation potential is motivated as follows: Regarding the market potential, a commercially viable innovation must demonstrate economic benefit. The greater the benefit, the more desirable and marketable an innovation is. At the same time, innovation commercialization process involves acquiring ideas about existing or potential market needs and looking for solutions satisfying them (Mitchell and Singh 1996). Thus, market potential reflects the likely economic or social value that can be generated by a new product or service (de Vries 2012). With respect to innovation readiness, successful launch of innovative products or services begins with the identification of technologies that are ready for commercialisation (Galbraith et al. 2006; Heslop et al. 2001). Frequently, innovation potential of innovations is assessed as low for novel technologies, at early stages of development. This is particularly true for the outcomes of research in universities and research institutes (Richard and Thursby 2001). Majority of such innovations are so underdeveloped that no one knows their commercial potential. Innovation readiness 
criterion refers to the technical maturity of an evolving innovation (Heslop et al. 2001). Finally, innovation management captures the level of a project participants' commitment to bring an innovation to the market, which is one of the key factors behind successful technology commercialisation (Kirchberger and Pohl 2016; Meseri and Maital 2001). The fact that the success of research collaborations depends largely on management issues was also confirmed for EU collaborative projects (Devenport et al. 1999). Below each criterion is described in a greater detail.

Innovation readiness This concept is related to the "technology readiness levels" (TRLs) framework introduced in the mid-1970s by NASA (Mankins 2009). By being discipline-independent, it was expected to allow more effective assessment of the maturity of new technologies. TRLs have been embraced by both private and public organizations, as it allows for highly effective communication of the status of new technologies among sometimes diverse organizations. Factors related to innovation readiness include, among others, the quality of the technology, age, scope, pioneering nature, and expected time to market. It aims to define the development phase of the innovation, e.g. conceptualization, experimentation or commercialisation. It also takes into account the steps that were taken in order to prepare innovation for commercialisation, e.g. prototyping, demonstration or testing activities or a feasibility study, and to secure the necessary technological resources, e.g. skills, to bring the innovation to the market. In addition, this criterion takes into account the development stage of an innovation and the time to its potential commercialisation.

Innovation management Innovation Management is related to the assessment and management of risks related to innovation commercialisation. It involves such measures as securing resources, organizing the process and setting milestones for technology transfer. This requires commitment from the top management (Nevens 1990). Also interactions with external actors, e.g. potential customers or users, increase the changes of a successful commercialization of technologies (Gerard et al. 2002). Thus, the concept of innovation management aims to capture the capability of the project's development and/or management team to execute the necessary steps to transform a novel technology or research results into a marketable product and, finally, to prepare its commercialisation. These steps may include, for example, clarifying the related ownership and IPR issues, preparing a business plan or market study, securing capital investment from public and/or private sources, or engaging an end-user in the project.

Market potential Market potential criterion relates to the demand and supply side of an innovation. Regarding the demand side, it concerns the prospective size of the market for a product and the chances of its successful commercialisation. Its aim is to assess how the product satisfies a market sector and to indicate that there is potential customer base. Market size and dynamics are among the most relevant factors behind a successful innovation commercialisation (Meseri and Maital 2001). With respect to the supply side, it aims to assess whether there are potential barriers, e.g. regulatory frameworks or existing IPR issues, which could weaken the commercial exploitation of an innovation. In the current undertaking, the focus is placed on the supply side. This is mostly related to the fact that information on markets for individual innovations is not available.

In order to observe and measure the above specified criteria, each of them was matched with relevant questions of the Innovation Radar Questionnaire (see Sect. 8). The outcome of the matching process is presented in Table 5 (see Sect. 8.2). Composite sub-indicators 
for each assessment criterion were recreated, i.e. Innovation Readiness Indicator (IRI), Innovation Management Indicator (IMI), and Market Potential Indicator (MPI). Each of the three indicators is an arithmetic aggregate of all relevant information in the domain of innovation readiness as defined in Sect. 4.1 and scoring system presented in Table 5 in Sect. 8.2. In the second step, the Innovation Potential Indicator (IPI) is constructed. IPI is an arithmetic composite indicator which aggregates the values of the sub-indicators.

An important issue related to the construction of composite indicators is the one of weighting. Unfortunately, no agreed methodology exists to weight individual indicators (EC-JRC 2005). In particular the context of the current study does not make the choice of a weighting scheme easy. All three elements are considered equally important for a successful innovation commercialization. Considering this, equal weighting is applied as follows:

$$
I P I=\frac{1}{3} I R I+\frac{1}{3} I M I \frac{1}{3} M P I .
$$

In order to make the values on each indicator among different innovations and innovators as easily comparable as possible, a normalisation procedure is applied. Observed values of each indicator are brought to the scale between 0 and 100 in the following way:

$$
I_{i \cdot \text { Normalized } \cdot \text { Score }}=\frac{I_{i \cdot \text { Observed } \cdot \text { Score }}}{I_{i \cdot \text { Max }} \text { Score }} \times 100,
$$

where $I_{i}$. is one of the innovation potential assessment indicators specified above.

\subsection{Organizational diversity}

In our study, we use different concept of organizations participating in innovation partnerships. Instead of relying on administrative information on project consortia, we use information on organizations that were identified by experts during project reviews as "key organisation(s) in the project delivering an innovation" (see the Innovation Radar innovation questionnaire in Sect. 8.1). The rationale behind identifying organizations in this way is to point at individual organizations among the consortium partners that play the most relevant role in innovation development. This way, our population includes participants to the FP7 projects that are considered as the main drivers of development of new technologies and innovations. This feature is unique among the studies analysing collaboration in research projects, which assume equal efforts and opportunities to appropriate their results. It introduces the notion of inequality and different incentives of organizations to participate and contribute to the consortium.

The project reviewers can identify up to three organizations per innovation. According to the FP procedures, there are five types of organizations that are eligible to participate to the research projects: High Education and Schools and Research Centres (HES/REC); Public Bodies (PUB); Small Medium Enterprise (SMEs); Large companies (LARGE) and Other organisations (NIL) (EC 2007). Based on this classification and on the fact that the IR provides information on up to three organizations involved in the development and delivering of an innovation, we distinguish between:

- Homogenous innovation partnerships, e.g. university and university or SME and SME, and

- Heterogeneous innovation partnerships, at least one university and one SME, or at least one SME and one large company. 
In addition, in order to control for the size of a partnership, in the proceeding analysis, we use a variable controlling for the number of key organizations to deliver the innovation.

\subsection{Data}

The data used in the current project was collected during periodic reviews of ICT FP7/CIP projects between 20 May 2014 and 19 January 2015 (see Table 2). The reviews were conducted by external experts commissioned by DG Connect. During this time, in addition to a standard review procedure, DG Connect deployed the Innovation Radar questionnaire (see Sect. 8) to spot innovations originating from the FP7 projects and the key organizations behind them. The research activities monitored are the ICT research actions and the e-Infrastructures activity under the Seventh Framework Programme 2007-2013 (under Cooperation and Capacities themes), and the policy support actions carried out under the Competitiveness and Innovation Framework Policy Support Programme (CIP ICT PSP).

In order to complement the survey data, information on FP7 projects' characteristics was retrieved from the CORDIS database (Mankins 2009). This database is the European Commission's public repository of information on all EU-funded research projects and their results. For the purpose of this study we retrieved, among others, information on the type and location of organizations that were identified as key organizations to bring the innovations to the market, EC funding and duration.

\section{Descriptive analysis}

According to Table 2, between May 2014 and January 2015, 279 projects were reviewed using the IR Questionnaire, i.e. 10.6\% of all ICT FP7, e-Infrastructures and CIP ICT PSP projects (EC-CONNECT 2013a). As a result, 517 innovations were identified. This means that, on average, an ICT FP7/CIP project produces nearly 2 innovations. The number of distinct organizations considered as key organisations in the project delivering these innovations amounted to 544. The average number of innovators per innovation was 1.23.

Table 3 reports the summary statistics of the three innovation potential assessment subindicators, i.e. Innovation Readiness (IRI), Innovation Management (IMI), Market Potential (MPI) and the composite Innovation Potential (IPI), for all analysed innovations and by innovation potential category. In addition, we show details on the key organizations in the project delivering an innovation, as identified during project reviews, and such project features as duration in months and total EC funding in Euro.

Table 2 Innovations in ICT FP7/CIP projects-key facts. Source: De Prato et al. (2015)

Review period

Number of reviewed projects

Number of innovations

Number of distinct innovators

Average number of innovations per project

Average number of innovators per innovation
20.05.2014 and 19.01.2015

279

517

544

1.85

1.23

Data: European Commission DG Connect 
Table 3 Descriptive statistics of the innovation potential assessment indicators. Source: De Prato et al. (2015) and own calculations

\begin{tabular}{|c|c|c|c|c|c|}
\hline & $\begin{array}{l}\mathrm{Nr} \text { of } \\
\text { innovations }\end{array}$ & Mean & SD & Min. & Max. \\
\hline \multicolumn{6}{|l|}{ Innovation assessment indicator } \\
\hline Innovation readiness & 517 & 36.49 & 21.72 & 2.5 & 100 \\
\hline Innovation management & 517 & 35.67 & 15.17 & 0 & 95 \\
\hline Market potential & 517 & 64.39 & 13.29 & 27.5 & 95 \\
\hline Innovation potential & 517 & 45.52 & 12.69 & 14.17 & 84.17 \\
\hline \multicolumn{6}{|c|}{ Key organisation(s) in the project delivering an innovation } \\
\hline $\begin{array}{l}\text { High education and schools and research } \\
\text { centres }\end{array}$ & 517 & 0.90 & 0.88 & 0 & 3 \\
\hline Public bodies & 517 & 0.02 & 0.16 & 0 & 2 \\
\hline Small medium enterprise & 517 & 0.45 & 0.65 & 0 & 3 \\
\hline Large companies & 517 & 0.35 & 0.63 & 0 & 3 \\
\hline Other organisations & 517 & 0.03 & 0.19 & 0 & 2 \\
\hline \multicolumn{6}{|l|}{ Project features } \\
\hline Duration & 517 & 36.79 & 6.54 & 18 & 67 \\
\hline EC funding in Euro & 496 & $543,203.50$ & $384,948.1$ & 0 & $2,851,000$ \\
\hline
\end{tabular}

Data: European Commission DG Connect

The table includes computations on innovation potential assessment indicators as defined in Sect. 4.1. Total number of reviewed projects: 279. Total number of innovations: 517. Review period: 20.05.2014 and 19.01.2015

The average value of the IPI among all the innovations is 45.52 out of the total 100 points. The innovation with the highest score obtained 84.17 points, while the lowestranked innovation only 14.17 points. When looking at the individual sub-indicators, one can observe that MPI has the highest and the IMI has the lowest average value. The average $M P I$ score is 64.39 and the average $I M P$ score is 35.67 points. The average score of the IRI is 36.49 points.

Based on the presented evidence, it can be concluded that, on average, market potential and innovation readiness are among the strongest dimensions of the innovations coming out of the reviewed ICT FP7/CIP projects. In contrast, innovation management represents the weakest dimension of these innovations.

Considering the type of organizations that are identified as "key organisation(s) in the project delivering an innovation", Table 3 shows that, on average, there are 0.9 university involved in an innovation developed within an FP7 project. In contrast, there are 0.45 SMEs per innovation and only 0.35 large companies per innovation. The involvement of other types of organizations, e.g. public bodies, is even less significant. As indicated by the values of standard deviation, there are considerable differences between innovations with respect to the type of organizations involved in their development. Thus, there are cases where only universities or only SMEs are indicated as the key organisations in delivering an innovation.

It is worth noting that SMEs accounted in FP7 for 16\% of total participations (2935 in total) and $14 \%$ of total EC funding ( $€ 850$ million in total) (EC-CONNECT 2013b). Hence, their involvement as key organizations in delivering innovations in FP7 projects is 
threefold higher than their participation rate. In comparison, High Education and Schools and Research Centres account for $29 \%$ of the total number of organizations, but they represent by far the most significant category of recipients in terms of funding (63\%) and large companies are the $29 \%$ of participating organisations and represent $20.5 \%$ of funding.

Regarding the relationship between the organizational diversity and the potential of innovations identified in EC-funded research projects, Fig. 1 presents average values of scores of individual indicators across distinct types of innovation partnerships. The largest average score of the IRI can be observed for innovation partnerships where at least two SMEs work together, i.e. 45 points. With on average 38.6 points on the IRI, innovations involving collaboration between universities and SMEs or between large companies rank second in terms of innovation readiness. The same pattern can be observed for the remaining indicators, except for the $M P I$, where innovations on which at least two large companies collaborate achieve the highest average score, i.e. 71 points. This finding reflects the higher market potential of innovations introduced by large companies. This indicates that collaborations between homogenous organizations are more likely to deliver innovations with higher potential for market commercialisation. This is particularly true for the collaboration between SMEs. Innovations developed between this type of companies are more likely to be technologically more mature. Moreover, the process of their commercialisation is likely to be better managed, as compared to innovations introduced by other types of collaboration arrangements. In other words, whenever an innovation is introduced, SMEs collaborating together are more likely to solve such issues as the question of innovation ownership, prepare business plan and market study or secure investment from public or private sources.

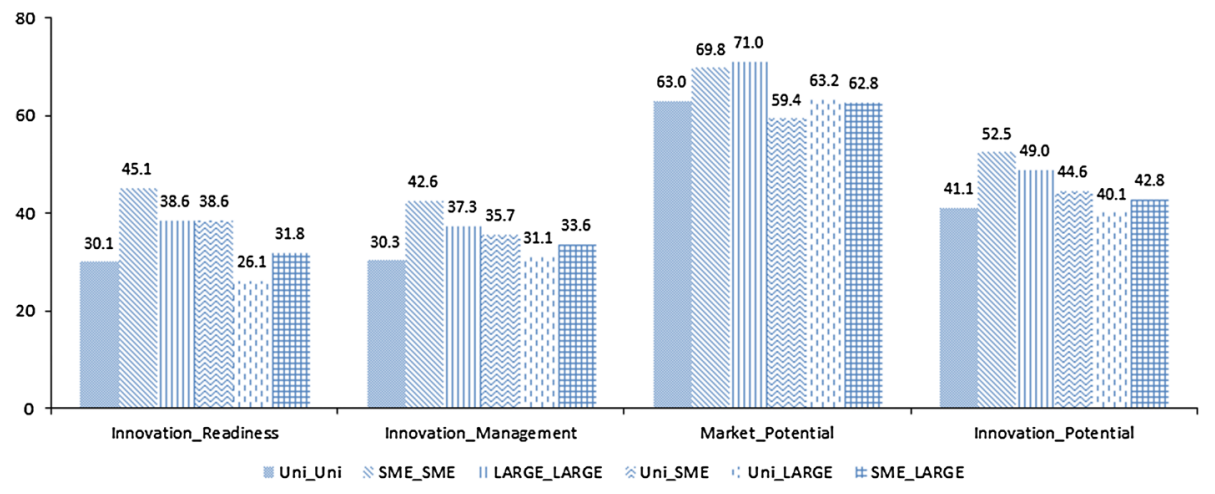

Fig. 1 Mean score of innovation potential assessment indicators across innovation partnerships. Note: The figure presents mean scores of four innovation potential assessment indicators, i.e. IRI, IMI, MPI and IPI, across distinct types of innovation partnerships. Total number of reviewed projects: 279. Total number of innovations: 517. Source: (De Prato et al. 2015) and own calculations. Data: European Commission DG Connect 


\section{Organizational diversity and innovation potential}

In order to explain the dependency between the potential of innovations developed in ICT FP7 projects and the type of partnership of organizations involved in their development, we define our dependent variable $y_{i}$ as one of the previously specified indicators of innovation potential, i.e. IRI, IMI, MPI and IPI (see Sect. 4.1). Among the independent variables there are six dummy variables that control for the type of partnerships of organizations that were identified by project reviewers as "key organisation(s) in the project delivering an innovation" (see Sect. 8.1). Three of these variables control for the existence of homogenous partnerships, i.e. University \& University, SME \& SME, Large \& Large. In each case, there are at least two organizations of the same type. The other three dummy variables control for the existence of heterogeneous partnerships, i.e. University \& SME, University \& Large and $S M E \&$ Large. In this case, the dummy variables take value 1 when there are at least two organizations belonging to different classes, e.g. one university and one SME, or SME and one large company. In addition, to control for the size of partnership we include the Number of key organizations variable, where the maximum is 3 .

First and Interim review dummy variables control for the maturity of the project. Each of them takes value 1 if the project is reviewed for the first or second time respectively and 0 otherwise. The reference group is in this case the final review of a project. Project funding and duration control for the amount of funding and duration of a project.

Table 4 reports the results of OLS estimations. Regarding the test of IRI, i.e. innovation readiness relating to the technical maturity of an evolving innovation, two variables controlling for the type of partnerships are statistically significant. SME\&SME variable has a positive and SME\&Large variable negative impact on the IRI score. In other words, homogenous partnerships of among SMEs are more likely to positively influence the technological maturity of an innovation. This involves such steps necessary to commercialise new products or service as prototyping, demonstration or testing activities or a feasibility study, and to secure the necessary technological resources, e.g. skills, to bring the innovation to the market. In contrast, the involvement of an SME and a large company in the development of new innovation is likely to slow down the process of technology maturing.

Relatively similar results are for the IMI that captures issues related to innovation management. Here, again, we can see that $S M E \& S M E$ has a positive and the SME\&Large variable negative impact on the IMI score. However, the Large\&Large variable has a positive influence on the likelihood of undertaking such steps as, for example, clarifying the related ownership and IPR issues, preparing a business plan or market study, securing capital investment from public and/or private sources, or engaging an end-user in the project. The results of the impact of the type of innovation partnership on the market potential are inconclusive.

In the final estimation, i.e. the aggregated innovation potential indicator, we can see that the existence of homogenous innovation partnerships of SMEs or large companies is positively related with innovation potential measured by IPI. In contrast, heterogeneous partnerships between SMEs and large companies seem to have a negative impact on the innovation potential. Because none of the variables controlling for the involvement of university as "a key organisation(s) in the project delivering an innovation" is statistically significant, no conclusions can be made. However, in all cases the sign of the coefficient controlling for the presence of a university in a partnership is negative. 
Table 4 Regressions on innovation potential indicators and innovation partnerships in EC-funded research projects. Source: Own calculations based on the data from Innovation Radar by DG Connect (De Prato et al. 2015) and Cordis (EC-CONNECT 2013a)

Innovation potential indicators

\begin{tabular}{llll}
\hline $\begin{array}{l}\text { Innovation } \\
\text { readiness }\end{array}$ & $\begin{array}{l}\text { Innovation } \\
\text { management }\end{array}$ & $\begin{array}{l}\text { Market } \\
\text { potential }\end{array}$ & $\begin{array}{l}\text { Innovation } \\
\text { potential }\end{array}$ \\
\hline
\end{tabular}

Type and number of organizations identified as key organizations to bring the innovation to the market

\begin{tabular}{|c|c|c|c|c|}
\hline University \& University & $\begin{array}{l}-2.840 \\
(5.560)\end{array}$ & $\begin{array}{l}3.572 \\
(3.957)\end{array}$ & $\begin{array}{l}-5.931 \\
(3.779)\end{array}$ & $\begin{array}{l}-1.733 \\
(3.267)\end{array}$ \\
\hline SME \& SME & $\begin{array}{l}11.319 * * \\
(5.451)\end{array}$ & $\begin{array}{l}14.647 * * * \\
(3.879)\end{array}$ & $\begin{array}{l}-0.214 \\
(3.706)\end{array}$ & $\begin{array}{l}8.584 * * * \\
(3.204)\end{array}$ \\
\hline Large \& Large & $\begin{array}{l}5.884 \\
(5.549)\end{array}$ & $\begin{array}{l}10.476^{* * * *} \\
(3.949)\end{array}$ & $\begin{array}{l}1.139 \\
(3.772)\end{array}$ & $\begin{array}{l}5.833 * \\
(3.261)\end{array}$ \\
\hline University \& SME & $\begin{array}{l}1.545 \\
(5.313)\end{array}$ & $\begin{array}{l}-4.580 \\
(3.781)\end{array}$ & $\begin{array}{l}1.003 \\
(3.612)\end{array}$ & $\begin{array}{l}-0.677 \\
(3.123)\end{array}$ \\
\hline University \& Large & $\begin{array}{l}-4.813 \\
(5.334)\end{array}$ & $\begin{array}{l}-3.854 \\
(3.796)\end{array}$ & $\begin{array}{l}3.482 \\
(3.626)\end{array}$ & $\begin{array}{l}-1.728 \\
(3.135)\end{array}$ \\
\hline SME \& Large & $\begin{array}{l}-10.417 * * \\
(5.128)\end{array}$ & $\begin{array}{l}-10.326 * * * \\
(3.650)\end{array}$ & $\begin{array}{l}-2.054 \\
(3.486)\end{array}$ & $\begin{array}{l}-7.599 * * \\
(3.014)\end{array}$ \\
\hline Number of key organizations & $\begin{array}{l}-2.202^{*} \\
(1.303)\end{array}$ & $\begin{array}{l}-4.139 * * * \\
(0.927)\end{array}$ & $\begin{array}{l}-3.291 * * * \\
(0.886)\end{array}$ & $\begin{array}{l}-3.211^{* * * *} \\
(0.766)\end{array}$ \\
\hline \multicolumn{5}{|c|}{ Review time-reference point: final review } \\
\hline First review & $\begin{array}{l}-17.624 * * * \\
(2.217)\end{array}$ & $\begin{array}{l}-5.479 * * * \\
(1.578)\end{array}$ & $\begin{array}{l}-2.697 * \\
(1.507)\end{array}$ & $\begin{array}{l}-8.600 * * * \\
(1.303)\end{array}$ \\
\hline Interim review & $\begin{array}{l}-13.908 * * * \\
(2.155)\end{array}$ & $\begin{array}{l}-5.895 * * * \\
(1.534)\end{array}$ & $\begin{array}{l}-0.597 \\
(1.465)\end{array}$ & $\begin{array}{l}-6.800 * * * \\
(1.267)\end{array}$ \\
\hline \multicolumn{5}{|l|}{ Project features } \\
\hline Project funding & $\begin{array}{l}0.000 \\
(0.000)\end{array}$ & $\begin{array}{l}0.000^{*} \\
(0.000)\end{array}$ & $\begin{array}{l}0.000 \\
(0.000)\end{array}$ & $\begin{array}{l}0.000 * \\
(0.000)\end{array}$ \\
\hline Project duration & $\begin{array}{l}-0.054 \\
(0.140)\end{array}$ & $\begin{array}{l}0.006 \\
(0.100)\end{array}$ & $\begin{array}{l}-0.005 \\
(0.095)\end{array}$ & $\begin{array}{l}-0.018 \\
(0.082)\end{array}$ \\
\hline Constant & $\begin{array}{l}46.815^{* * * *} \\
(6.753)\end{array}$ & $\begin{array}{l}35.088^{* * *} \\
(4.806)\end{array}$ & $\begin{array}{l}74.970 \text { *** } \\
(4.591)\end{array}$ & $\begin{array}{l}52.291 * * * \\
(3.969)\end{array}$ \\
\hline $\mathrm{N}$ & 496 & 496 & 496 & 496 \\
\hline Prob $>$ F & 0.000 & 0.000 & 0.000 & 0.000 \\
\hline $\mathrm{R}^{2}$ & 0.208 & 0.165 & 0.234 & 0.234 \\
\hline Adjusted $\mathrm{R}^{2}$ & 0.190 & 0.150 & 0.217 & 0.217 \\
\hline
\end{tabular}

The dependent variable is the score in individual innovation potential assessment criteria and the final composite index of innovation potential, as defined in Sect. 4.1. The list of explanatory variables includes: First, a set of variables on the type and number of organizations identified as key organizations to bring the innovation to the market, i.e. where with the at most three key organizations to bring the innovation to the market are such combinations as two universities (University \& University), SMEs (SME \& SME), large companies (LARGE \& LARGE) or at least one university and one SME (University \& SME), or at least one university and one large company (University \& LARGE) or at least one SME and one large company (SME \& LARGE), and the number of key organizations to bring the innovation to the market (number of key organizations). Second, information on the project review time, where the reference point is the final review. Third, such project features as project funding and duration

All models report OLS regression estimates. Standard errors are reported in parentheses

*** Significant at the $1 \%$ level

** Significant at the $5 \%$ level

* Significant at the $10 \%$ level 
Regarding the overall number of organizations involved in delivering an innovation in a FP7 project, it can be seen that for all measures of innovation potential it has negative impact. The same observation can be made with respect to the review time. As compared to the final review, coefficients of dummies controlling for the first and interim review are negative. In other words, we can say that the innovations mature and increase their potential, as projects progress.

Concerning the remaining features of the project, we can say that, overall, neither project funding nor duration has an impact on the measures of innovation potential. Though very small, only the variable controlling for project funding has a positive impact on the $I M I$ and $I P I$.

\section{Conclusions}

The current paper uses data collected in a formal process of identifying and assessing the potential of innovations developed within EC-funded projects. Knowing that project consortia are characterised by a high level of organizational heterogeneity, we analyse the question of what is the relationship between the organizational diversity and the innovation potential. The current work differs from most of the existing research on RJV in two aspects. First, it looks at the innovative output of research collaborations. Analysing innovative rather than, for example, financial outcomes allows us to assess the transformative effect of publically-funded research. Second, we look at the performance at the project level, rather than at benefits of individual participants.

Our results show that the composition of innovation partnerships has an impact on the innovation potential of innovations developed in publically-funded research projects. The innovative potential of research output of homogenous partnerships, e.g. between two SMEs or two large companies, is likely to be higher, as compared to heterogeneous partnerships, e.g. an SME and a large company.

The above point is mainly visible in the context of innovation readiness and innovation management. The concept of innovation readiness covers such issues as prototyping, demonstration or testing activities or a feasibility study, and to secure the necessary technological resources, e.g. skills, to bring the innovation to the market. Innovation management refers to the capability of the project's team to execute the necessary steps to transform a novel technology or research results into a marketable product and to commercialise it. Such steps may include, for example, clarifying the related ownership and IPR issues, preparing a business plan or market study, securing capital investment from public and/or private sources, or engaging an end-user in the project. Our results suggest that that, due to, for example, coordination problems or differences in organizational processes, organizations of the same type, e.g. two SMEs or two large organizations, are more likely to find solutions to the problems that may arise when bringing an innovation to the market.

Considering that we find that neither project funding nor duration affects the potential of innovation, we conclude that the design of a consortium is more important than the level of R\&D input in explaining its innovative performance. In addition to technological and product market proximity of members, reported previously as relevant for the outcomes of collaboration (Branstetter and Sakakibara 2002), we can also add that the organizational diversity of members plays a role for the positive outcomes of such collaborations. 
We can conclude that differences in innovation performance of RJV result from various capabilities, motivations and needs related to technology of different types of organizations. For example, we show that innovations (co-)developed by SMEs exhibit high commercialisation potential. This is consistent with the previous findings suggesting that, when participating in publically-funded research projects, small companies have very explicit goals (Polt et al. 2008). Although large firms are also likely to deliver innovations with high potential, it is unlikely that this will take place in collaboration with a smaller partner or a university. They adopt a strategy focused on technology watch and active acquisition of new knowledge from partners, rather than joint development and commercialisation of a novel technology (Hernan et al. 2003; Röller et al. 2007). What is worth noting is the fact that although universities alone are not particularly likely to introduce ready to commercialize innovations (Carayol 2003). Universities often report partnership with other companies as the main need to bring their innovations to the market (Pesole and Nepelski 2016). They also tend to report more needs related to the finalisation of the innovation and the subsequent steps to bring it to the market, while private organisations needs are more relate to the commercialization of the innovation and the need to create or expand their market, i.e. scaling-up.

The results imply that organizations joining research consortia need to be aware of these differences and find a way to ensure the right balance between technological and technology commercialisation capabilities available in a consortium. Policy makers also need to take into account these peculiarities. The process of designing support mechanisms for technology commercialisation should account for the diversity of needs related to different types of organizations and partnerships.

Our research has some limitations. First of all, it makes use of survey data, which provides only very limited information about the actual content of the innovative output. This, for example, does not allow us to quantify the economic value of innovations. Also the framework used to assess the innovative potential reduces the richness of innovative activity. It does not distinguish, for example, between radical and incremental innovations. Finally, both the innovation questionnaire and the assessment framework focus on applied and marketable outcomes of research projects. This naturally favours private organizations and, hence, projects that are dominated by firms.

Regarding further extension of the current work, we believe that it would benefit from extensions that account for, example, for technological relatedness of participating organizations. Also controlling for the geographic origin of the participants would allow to cast some light on the role of physical proximity and coordination cost in the working of research consortia.

Open Access This article is distributed under the terms of the Creative Commons Attribution 4.0 International License (http://creativecommons.org/licenses/by/4.0/), which permits unrestricted use, distribution, and reproduction in any medium, provided you give appropriate credit to the original author(s) and the source, provide a link to the Creative Commons license, and indicate if changes were made. 


\section{Appendix}

\section{Innovation Radar Questionnaire}

\section{Innovation Radar Questionnaire by EC DG CONNECT}

Note: the first 16 questions below are to be answered for each innovation the project develops (up to a maximum of 3 innovations).

1) Describe the innovation (in less than $\mathbf{3 0 0}$ characters, spaces included):

2) Is the innovation developed within the project...:
a) Under development
b) Already developed but not yet being exploited
c) being exploited

3) Characterise the type of innovation (only to be answered if $\mathbf{2 b}$ or $2 \mathrm{c}$ is selected)

- Significantly improved product

- New product

- Significantly improved service (except consulting ones)

- New service (except consulting ones)

- Significantly improved process

- New process

- Significantly improved marketing method

- New marketing method

- Significantly improved organisational method

- New organisational method

- Consulting services

- Other

4) If other, please specify:

5) Characterise the macro type of innovation (only to be answered if "under development" is selected for Q2):

- Product

- Marketing method

- Organisational method

- Process

- Service (non-consulting)

- Consulting service

- Do not know yet

6) Will the innovation be introduced to the market or deployed within a partner:
a) Introduced new to the market (commercial exploitation)
b) Deployed within a partner (internal exploitation: Changes in organisation, new internal processes implemented, etc.)
c) No exploitation planned

7) If no exploitation planned, please explain why no exploitation is planned (answer only if 6(c) is selected)

8) Is there a clear owner of the innovation in the consortium or multiple owners?

- A clear owner

- Multiple owners

9) Indicate who is the "owner" of the innovation: ... 
10) Indicate the step(s) already done (or are foreseen) in the project in order to bring the innovation to (or closer to) the market (answer only if $6(\mathrm{a})$ is selected)

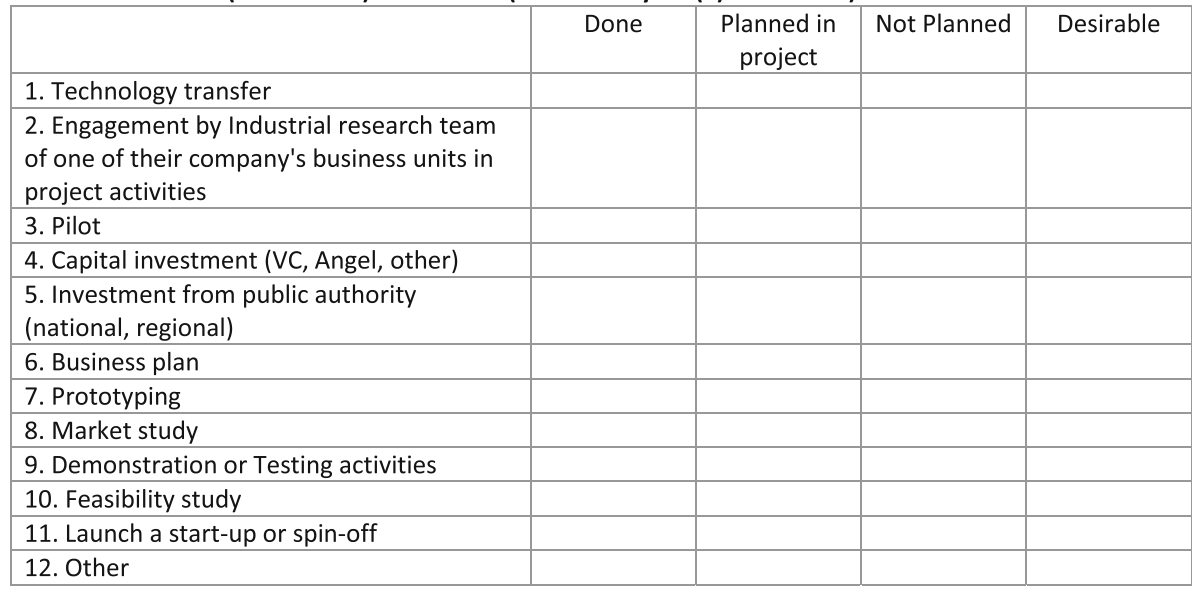

\section{1) If other, please specify}

12) Indicate which participant(s) (up to a maximum of 3) is/are the key organisation(s) in the project delivering this innovation. For each of these identify under the next question their needs to fulfil their market potential.

Org1:

Org2:

Org3:

13) Indicate their needs to fulfil their market potential

\begin{tabular}{|l|c|c|c|c|c|l|l|l|l|}
\hline & $\begin{array}{c}\text { Investor } \\
\text { readiness } \\
\text { training }\end{array}$ & $\begin{array}{c}\text { Investor } \\
\text { introductio } \\
\text { ns }\end{array}$ & $\begin{array}{c}\text { Biz plan } \\
\text { developme } \\
\text { nt }\end{array}$ & $\begin{array}{c}\text { Expanding } \\
\text { to more } \\
\text { markets }\end{array}$ & $\begin{array}{c}\text { Legal } \\
\text { advice(IPR } \\
\text { or other) }\end{array}$ & Mentoring & $\begin{array}{c}\text { Partnership } \\
\text { with other } \\
\text { company } \\
\text { (technolog } \\
\text { y or other) }\end{array}$ & Incubation & $\begin{array}{c}\text { Startup } \\
\text { accelerator }\end{array}$ \\
\hline Org 1 & & & & & & & & & \\
\hline Org 2 & & & & & & & & & \\
\hline Org 3 & & & & & & & & & \\
\hline
\end{tabular}

14) When do you expect that such innovation could be commercialised? (answer only if 6(a) is selected)

- Less than 1 year

- $\quad$ Between 1 and 2 years

- $\quad$ Between 3 and 5 years

- More than 5 years

15) Have any of the project partners...

(only to be answered if "Done" or "Planned in Project" is chosen for 10.5 "Investment from public authority")

a) already applied for support from private investors

b) already applied for investement from public authorities

c) Planning to start discussions with private or public investors

\section{6) Which partners are in discussion with investors (or are planning such discussions)?}

(the above questions are to be answered for each innovation developed by the project, up to a maximum of 3 innovations) 


\section{General Questions}

(questions below are to be answered once in the project review, not for each innovation)

1) How does the consortium engage end-users?

- End user organisation in the consortium

- An end user organisation outside of the consortium is consulted

- No end user organisation in the consortium or consulted

2) Are there in the consortium internal IPR issues that could compromise the ability of a project partner to exploit new products/solutions/services, internally or in the market place?

- yes

- no

3) Please provide specifics of the IPR issues:

4) Which are the external bottlenecks that compromise the ability of project partners to exploit new products, solutions or services, internally or in the market place?

- IPR

- Standards

- Regulation

- Financing

- Workforce's skills

- Trade issues (between MS, globally)

- Others

5) Indicate how many patents have been applied for by the project:

6) Does the review panel consider the project performance in terms of innovation?

- Exceeding expectations

- Meeting expectations

- Performing below expectations

7) General observations of innovation expert on this project's innovation performance:

8) How would you rate the level of commitment of relevant partners to exploit the innovation?

- Very low

- Low

- Average

- High

- Very High

- None

9) Please indicate the 1 partner (excluding large enterprises) that the panel considers to be the most impressive in terms of innovation potential:

10) Please enter some tag words (comma separated) to represent what "innovation elements" are strong in the project:

11) Please enter some tag words (comma separated) to represent what "innovation elements" can be improved (or are absent) in the project:

\section{Innovation potential assessment framework}

Table 5 presents the result of matching assessment criteria defined in Sect. 4.1 with relevant questions of the Innovation Radar Questionnaire. 
Table 5 Innovation potential assessment framework

\begin{tabular}{lll}
\hline Criteria and questions & Scoring & Question \\
& Max: \\
code $^{\text {a }}$ & 10
\end{tabular}

\section{Market potential}

Type of innovation (if Q2b or Q2c selected)

Q3

New product, process or service 1

Significantly improved product, process or service

New marketing or organizational method

Significantly improved marketing or organizational method, other

Consulting services

Type of innovation (if Q2a selected):

Q5

Product or service

Process, marketing or organizational method

0

Consulting services

0

Innovation exploitation

Q6

Commercial exploitation

1

Internal exploitation

No exploitation

External bottlenecks

GQ4

No external IPR issues that could compromise the ability of a project partner to exploit the innovation

No standards issues that could compromise the ability of a project partner to GQ4b exploit the innovation

No regulation issues that could compromise the ability of a project partner to exploit the innovation

No financing issues that could compromise the ability of a project partner to exploit the innovation

No trade issues that could compromise the ability of a project partner to exploit the innovation

No other issues that could compromise the ability of a project partner to exploit the innovation

Needs of key organizations

No investor readiness training need

No investor introductions need

Q13b

No biz plan development need

Q13c

No expanding to more markets need

Q13d

No legal advice (IPR or other) need

Q13e

No mentoring need

Q13f

No partnership with other company (technology or other) need

Q13 g

No incubation need

Q13 h

No startup accelerator need

Q13i

Number of patents have been applied for by the project

GQ5 
Table 5 continued

Criteria and questions

Scoring

Question Max:

$\operatorname{code}^{\mathrm{a}}$

\section{Innovation readiness}

Development phase

Q2

Under development

0

Developed but not exploited

Being exploited

Technology transfer ${ }^{b}$

Q10.1

Done

Planned

Pilot $^{\text {b }}$

Q10.3

Done

Planned

Prototyping $^{\mathrm{b}}$

Q10.7

Done

Planned

Demonstration or testing activities ${ }^{\mathrm{b}}$

Q10.9

Done

Planned

Feasibility study ${ }^{\mathrm{b}}$

Q10.10

Done

Planned

Other $^{\mathrm{b}}$

Q10.12

Done

Planned

Time to market

Q14

Less than 1 year

Between 1 and 2 years

Between 3 and 5 years

More than 5 years

No workforce's skills issues that could compromise the ability of a project partner to exploit the innovation

\section{Innovation Management}

There is a clear owner of the innovation

Q8

Business plan ${ }^{\mathrm{b}}$

Q10.6

Done

Planned

Market study ${ }^{\mathrm{b}}$

Q10.8

Done

Planned

Launch of a start-up or spin-off ${ }^{\mathrm{b}}$

Q10.11

Done 
Table 5 continued

\begin{tabular}{|c|c|c|}
\hline Criteria and questions & $\begin{array}{l}\text { Scoring } \\
\text { Question } \\
\text { code }^{\mathrm{a}}\end{array}$ & $\begin{array}{l}\text { Max: } \\
10\end{array}$ \\
\hline $\begin{array}{l}\text { No consortium internal IPR issues that could compromise the ability of a project } \\
\text { partner to exploit the innovation }\end{array}$ & GQ2 & 1 \\
\hline Company's business unit involved in project activities ${ }^{\mathrm{b}}$ & Q10.2 & \\
\hline Done & & 1 \\
\hline Planned & & 0.5 \\
\hline Capital investment ${ }^{\mathrm{b}}$ & Q10.4 & \\
\hline Done & & 1 \\
\hline Planned & & 0.5 \\
\hline Investment from public authority ${ }^{\mathrm{b}}$ & Q10.5 & \\
\hline Done & & 1 \\
\hline Planned & & 0.5 \\
\hline End-user engagement & GQ1 & \\
\hline End-user in the consortium & & 1 \\
\hline End-user consulted & & 0.5 \\
\hline No end-user in the consortium or consulted & & 0 \\
\hline Commitment of relevant partners to exploit innovation & GQ8 & \\
\hline Above average & & 1 \\
\hline Average & & 0.5 \\
\hline Below average & & 0 \\
\hline
\end{tabular}

${ }^{a} G Q$ general questions

${ }^{\mathrm{b}}$ Steps DONE in the project in order to bring the innovation to the market

\section{References}

Aguiar, L., \& Gagnepain, P. (2013). European cooperative R\&D and firm performance. Universidad Carlos III de Madrid. Departamento de Economía.

Amason, A., Shrader, R., \& Tompson, G. (2006). Newness and novelty: Relating top management team composition to new venture performance. Journal of Business Venturing, 21(1), 125-148.

Ancona, D., \& Caldwell, D. (1992). Demography and design: Predictors of new product team performance. Organization Science, 3(3), 321-341.

Asheim, B., Boschma, R., \& Cooke, P. (2011). Constructing regional advantage: Platform policies based on related variety and differentiated knowledge bases. Regional Studies, 45(7), 893-904.

Audretsch, D. B., \& Link, A. N. (Eds.). (2016). Essays in public sector entrepreneurship. Berlin: Springer.

Barajas, A., Huergo, E., \& Moreno, L. (2012). Measuring the economic impact of research joint ventures supported by the EU Framework Programme. The Journal of Technology Transfer, 37(6), 917-942.

Barkema, H., \& Shvyrkov, O. (2007). Does top management team diversity promote or hamper foreign expansion? Strategic Management Journal, 28(7), 663-680.

Bayona-Sáez, C., \& García-Marco, T. (2010). Assessing the effectiveness of the Eureka Program. Research Policy, 39(10), 1375-1386.

Belderbos, R., Carree, M., \& Lokshin, B. (2004). Cooperative R\&D and firm performance. Research Policy, 33(10), 1477-1492.

Boeker, W. (1997). Executive migration and strategic change: The effect of top manager movement on product-market entry. Administrative Science Quarterly, 42(2), 213-236.

Branstetter, L., \& Sakakibara, M. (2002). When do research consortia work well and why? Evidence from Japanese panel data. American Economic Review, 92(1), 143-159. 
Bronwyn, H., Link, A., \& Scott, J. (2003). Universities as research partners. The Review of Economics and Statistics, 85(2), 485-491.

Caloghirou, Y., Tsakanikas, A., \& Vonortas, N. (2001). University-industry cooperation in the context of the European Framework Programmes. The Journal of Technology Transfer, 26(1-2), 153-161.

Carayol, N. (2003). Objectives, agreements and matching in science-industry collaborations: reassembling the pieces of the puzzle. Research Policy, 32(6), 887-908.

Chun, H., \& Mun, S. (2012). Determinants of R\&D cooperation in small and medium-sized enterprises. Small Business Economics, 39(2), 419-436.

Cooper, R. G., \& Kleinschmidt, E. J. (1997). Winning businesses in product development: The critical success factors. The Journal of Product Innovation Management, 14(2), 132.

Cox, T. (1993). Cultural diversity in organizations: Theory, research and practice. San Francisco, CA: Barrett-Koehler.

Cunningham, J., \& Link, A. (2015). Fostering university-industry R\&D collaborations in European Union countries. International Entrepreneurship and Management Journal, 11(4), 849-860.

Davenport, S., Davies, J., \& Grimes, C. (1998). Collaborative research programmes: Building trust from difference. Technovation, 19(1), 31-40.

De Coster, R., \& Butler, C. (2005). Assessment of proposals for new technology ventures in the UK: Characteristics of university spin-off companies. Technovation, 25(5), 535-543.

De Prato, G., Nepelski, D., \& Piroli, G. (2015). Innovation radar: Identifying innovations and innovators with high potential in ICT FP7, CIP \& H2020 projects. Seville: JRC-IPTS.

de Vries, B. (2012). Assessment of market potential for innovations with new technology in an existing market. MSc thesis, University of Twente, Twente. Retrieved from http://essay.utwente.n1/62374/.

Devenport, S., Davies, J., \& Grimes, C. (1999). Collaborative research programmes: Building trust from difference. Technovation, 19(1), 31-40.

Diánez-González, J.-P., \& Camelo-Ordaz, C. (2016). How management team composition affects academic spin-offs' entrepreneurial orientation: The mediating role of conflict. The Journal of Technology Transfer, 41(3), 530-557.

EC. (2007). FP7 in brief. How to get involved in the EU 7th Framework Programme for Research. Luxembourg: Office for Official Publications of the European Communities.

EC. (2015). A new role for EU Research and Innovation in the benefit of citizens: Towards an open and transformative R\&I policy. In RTD (Ed.), Policy paper by the research, innovation, and science policy experts. Brussels: European Commission.

EC-CONNECT. (2013a). FP7-ICT-projects-partners-database-2007-2013.

EC-CONNECT. (2013b). Overview of research projects in the ICT Domain 2012. ICT statistical report for annual monitoring (StReAM): European Commission.

EC-CONNECT. (2014). Analysis of publications and patents of ICT research in FP7. Brussels: European Commission DG Communications Networks, Content \& Technology.

EC-JRC. (2005). Tools for composite indicators building. Ispra: European Commission, JRC.

Galbraith, C., Ehrlich, S., \& DeNoble, A. (2006). Predicting technology success: Identifying key predictors and assessing expert evaluation for advanced technologies. The Journal of Technology Transfer, 31(6), 673-684.

Georghiou, L. (1999). Socio-economic effects of collaborative R\&D_European experiences. The Journal of Technology Transfer, 24(1), 69-79.

Gerard, G., Shaker, Z., \& Robley, W. (2002). The effects of business-university alliances on innovative output and financial performance: A study of publicly traded biotechnology companies. Journal of Business Venturing, 17(6), 577-609.

Hagedoorn, J., Link, A., \& Vonortas, N. (2000). Research partnerships. Research Policy, 29(4-5), 567-586.

Hernan, R., Marin, P., \& Siotis, G. (2003). An empirical evaluation of the determinants of research joint venture formation. The Journal of Industrial Economics, 51(1), 75-89.

Heslop, L., McGregor, E., \& Griffith, M. (2001). Development of a technology readiness assessment measure: The cloverleaf model of technology transfer. The Journal of Technology Transfer, 26(4), 369-384.

Hewitt-Dundas, N., Gkypali, A., \& Roper, S. (2017). Accessibility, utility and learning effects in universitybusiness collaboration. Enterprise Research Centre.

JRC. (2014). The 2014 PREDICT report. An analysis of ICT R\&D in the EU and beyond. Seville: European Commission, JRC.

Kastrinos, N. (1994). Issues of exploitation: Evaluating the impact of the European Community Framework Programme on European industry. Technovation, 14(10), 679-688.

Katz, M. (1986). An analysis of cooperative research and development. The Rand Journal of Economics, 17(4), 527-543. 
Khurana, A., \& Rosenthal, S. R. (1998). Towards holistic "front ends" in new product development. The Journal of Product Innovation Management, 15(1), 57-74.

Kirchberger, M., \& Pohl, L. (2016). Technology commercialization: A literature review of success factors and antecedents across different contexts. The Journal of Technology Transfer, 41(5), 1077-1112.

Knight, D., Pearce, C., Smith, K., Olian, J., Sims, H., Smith, K., et al. (1999). Top management team diversity, group process, and strategic consensus. Strategic Management Journal, 20(5), 445-465.

Kogut, B. (1988). Joint ventures: Theoretical and empirical perspectives. Strategic Management Journal, 9(4), 319-332.

Leyden, D. (2016). Public-sector entrepreneurship and the creation of a sustainable innovative economy. Small Business Economics, 46(4), 553-564.

Leyden, D., \& Link, A. (2013). Knowledge spillovers, collective entrepreneurship, and economic growth: The role of universities. Small Business Economics, 41(4), 797-817.

Leyden, D., \& Link, A. (2015). Public sector entrepreneurship: US technology and innovation policy. New York: Oxford University Press.

Liao, P., \& Witsil, A. (2008). A practical guide to opportunity assessment methods. Research Triangle Park, NC: RTI Press.

Link, A. (2015). Capturing knowledge: Private gains and public gains from university research partnerships. Foundations and Trends in Entrepreneurship, 11(3), 139-206.

Link, A. (2016). Public sector entrepreneurship: Introduction to the special section. Economia e Politica Industriale, 43(4), 355-356.

Link, A., \& Rees, J. (1990). Firm size, university based research, and the returns to R\&D. Small Business Economics, 2(1), 25-31.

Link, A., \& Ruhm, C. (2009). Bringing science to market: Commercializing from NIH SBIR awards. Economics of Innovation and New Technology, 18(4), 381-402.

Link, A., \& Scott, J. (2004). Evaluating public sector R\&D programs: The advanced technology program's investment in wavelength references for optical fiber communications. The Journal of Technology Transfer, 30(1), 241-251.

Link, A., \& Scott, J. (2005). Universities as partners in U.S. research joint ventures. Research Policy, 34(3), 385-393.

Link, A., \& Siegel, D. (2005). Generating science-based growth: An econometric analysis of the impact of organizational incentives on university-industry technology transfer. The European Journal of Finance, 11(3), 169-181.

Mankins, J. (2009). Technology readiness assessments: A retrospective. Acta Astronautica, 65(9-10), $1216-1223$.

Mazzucato, M. (2013). The entrepreneurial state: Debunking public vs. private sector myths. London: Anthem Press.

Mazzucato, M. (2016). From market fixing to market-creating: A new framework for innovation policy. Industry and Innovation, 23(2), 140-156.

Meseri, O., \& Maital, S. (2001). A survey analysis of university-technology transfer in Israel: Evaluation of projects and determinants of success. The Journal of Technology Transfer, 26(1), 115-125.

Mitchell, W., \& Singh, K. (1996). Survival of businesses using collaborative relationships to commercialize complex goods. Strategic Management Journal, 17(3), 169-196.

Nevens, M. (1990). Commercializing technology: What the best companies do. Planning review, 18(6), 20-24.

Okamuro, H. (2007). Determinants of successful R\&D cooperation in Japanese small businesses: The impact of organizational and contractual characteristics. Research Policy, 36(10), 1529-1544.

Pandza, K., Wilkins, T., \& Alfoldi, E. (2011). Collaborative diversity in a nanotechnology innovation system: Evidence from the EU Framework Programme. Technovation, 31(9), 476-489.

Perkins, D., \& Fields, D. (2010). Top management team diversity and performance of Christian churches. Nonprofit and Voluntary Sector Quarterly, 39(5), 825-843.

Pesole, A., \& Nepelski, D. (2016). Universities and collaborative innovation in EC-funded research projects: An analysis based on Innovation Radar data. EC-JRC.

Polt, W., Vonortas, N., \& Fisher, R. (2008). The impact of publicly funded research on innovation: An analysis of European Framework Programmes for Research and Development. European Commission, Directorate-General for Internal Market, Industry, Entrepreneurship and SMEs.

Richard, J., \& Thursby, M. (2001). Proofs and prototypes for sale: The licensing of university inventions. American Economic Review, 91(1), 240-259.

Röller, L.-H., Siebert, R., \& Tombak, M. (2007). Why firms form (or do not form) RJVS*. The Economic Journal, 117(522), 1122-1144. 
Sakakibara, M. (1997). Heterogeneity of firm capabilities and cooperative research and development: An empirical examination of motives. Strategic Management Journal, 18(S1), 143-164.

Santoro, M., \& Chakrabarti, A. (2002). Firm size and technology centrality in industry-university interactions. Research Policy, 31(7), 1163-1180.

Siebert, R. (1996). The impact of research joint ventures on firm performance: An empirical assessment. Berlin: Wissenschaftszentrum Berlin (WZB).

Tödtling, F., \& Trippl, M. (2005). One size fits all?: Towards a differentiated regional innovation policy approach. Research Policy, 34(8), 1203-1219. 